\title{
TRIZ Routes the Solving Process of Innovation Problem
}

\author{
Wang Qing, Bai Na, Bai Jingru, and Jia Chunxia \\ Energy and Power College, Northeast Dianli University, Jilin, China \\ rlx888@126.com,303516467@qq.com, bai630@mail.nedu.edu.cn,jiachunxia_215@126.com
}

\begin{abstract}
:
Innovation is not only a concept, but also a mature theoretical system. It has specific implementation methods and tools. Therefore, the capacity of innovation can be aroused and cultivated by a way of students' innovation education. This paper simply introduces the theory of TRIZ to solve the problem of innovation and an efficient innovative method - Mind Mapping. How to make the solving of innovation problem modeled. We put forward an effective mode of innovative education at the end of the article, so that students in scientific research and production practice, to cultivate practical ability to innovate.
\end{abstract}

Keywords: $\quad$ TRIZ; $\quad$ Mind $\quad$ Mapping; innovation-education mode

\section{THE NECESSITY AND FEASIBILITY OF INNOVATION EDUCATION}

Innovation is the foundation of a country to be strong and a people to be prospective[1]. The implementation of innovative education is the only way to improve nationally innovative ability. The cultivation of innovative ability is the core of innovation education. Innovation education is based on the theory of innovation, and cultivates students to have certain innovative consciousness, innovative thinking and innovative ability. The students firmly and systematic master the knowledge and develop their innovative ability at the same time. Everyone has the potential ability to innovate, but innovative ability needs stimulating, and also can be stimulated by the means of training; innovative education can make people have a strong ability to innovate.
There are more than 300 original inventions, creations and innovations of technology in the world, such as the famous trial and error, brainstorming, hotan twelve method, etc. The invented methods help the people produce inventions and innovations. But more than the vast majority of innovative techniques is abstract, blind and random, the direction is not clear.

The emergence of epoch-making "Theory of Invention Problem Solving" - TRIZ (The found of Inventive Problem Solving) provides people with a new set of innovation theory and technology, and opens up a new era of human innovation[3].

TRIZ is proposed by G.S.A ltshuller since 1946[4], and sums up more than 250 patents in the world literature collection by researching, processing, and summaring the theory, method and system to solve the problem of the invention after more than 50 years . The study found that: the development of science and technology system is not random, but follows certain evolutionary laws. People can predict the future development direction of technology systems according to the evolutionary laws. They also found that technological innovation faces the sirmilarly primary problems and contradictions, and a lot of innovation process have the similar thinking to solve the problem.

Innovation education is to pass on this scientific innovation- theory and advanced innovative ways to students to master good innovative technology, raising the successful rate of to innovation and level. 


\section{THE THEORETICAL FOUNDATION OF THE INNOVATION EDUCATION}

\subsection{TRIZ THEORY}

TRIZ is a scientific creation methodology. It is based on the inner objective laws of technology system evolution, comprehensive to logic analysis and problem solution. It can be directed to guide people to innovation step by step, rather than blindly, casually. It provides a range of tools, including 40 principle of Solving technical contradictions and conflict matrix, to solve the contradictory between physical four separation principle and 11 methods , 76 standard of solution and the algorithm of invention Problem Solving (ARIZ Alqorithm of Inventive Problem Solving), as well as tools and resources to eliminate the psychological inertia, time - cost operator, etc. It makes people operate and execute in different stages and different time in accordance with the different methods to solve the problem. Therefore, the invention can be quantified and controlled; rather than simply invented by inspiration and understanding.

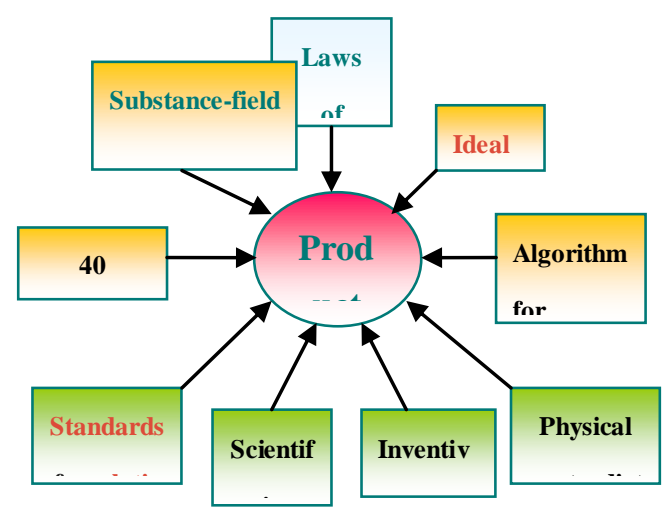

Figure 1. TRIZ theoretical system

People can break the mindset, broaden the train of thought, and right to find the problems existing in the product or system and technique-innovation thinking, and find innovative solutions with the aid of TRIZ theory. TRIZ can effectively eliminate boundaries between the different disciplines. the engineering and creative training at the same time. it also make the problem get a innovative solution.

\subsection{MING MAPPING}

Mind Mapping, also called Mental Map, is an graphical tool of thinking which can express radioactive thinking effectively .it is simple but very effective, and is a revolutionary tool of thinking. Mind mapping using graphic and skills, shows the relationship between the various topics with each other affiliated with related hierarchy figure, to subject keywords to a memory link with image, color, etc. mind mapping uses brain function and the laws of memory when you are reading and thinking, to help people balance the development between logic and imagination in the art and science, thus opening the infinite potential of human brain. Mind Map so it is the power of the human mind.

Mind Mapping is a method of radioactive thinking embodied. We know that radioactive thinking is a natural way of thinking of the human brain. Each kind of information into the brain, whether it is a feeling, memory, or idea, including text, numbers, codes, food, fragrance, lines, color, imagery, rhythm, musical notes, etc., can become a thinking center, and center radiate outward thousands of key points, and each key represents a link with a central theme, and each link can be another central theme, then emanate outward thousands of key points, and present a radioactive three-dimensional structure. Links and the joints can be regarded as the memory of you, that is your personal database. Humans began to accumulate born with these large and complex database. Brain amazing ability can not only store that we have accumulated a huge mass of data, through the mind map of radioactive thinking method, in addition to accelerate information cumulants, but also classify the data according to the correlation to increase operation efficiency of brain by making data storage, management and application more systematic . At the same time, Mind Map can make good use of the function of the left and right brain, by the use of color, images, code, can not only help us memory, improve our creativity, also let mind mapping be more fun, with individual characteristics and multifaceted. 


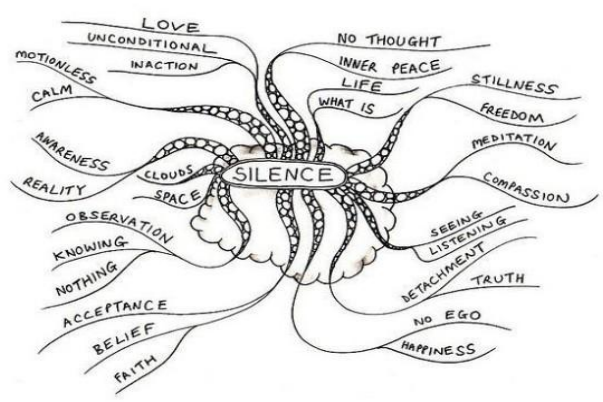

Figure 2.Mind Mapping ahout silence

Therefore, Mind Mapping is a method which you can perform intellectual potention extremely. it can enhance thinking skills, greatly improving memory ,the organization ability and creativity. It has a quantum jump compsred with the traditional notes and learning method, mainly because it comes from brain physiology interactive mode of learning, and carrys out life to have radioactive thinking ability and the multi-sensory learning characteristics.

\section{THE PATTEM OF INNOVATION EDUCATION}

All innovations must satisfy three conditions: the creative motivation and desire, theory and method based on scientific knowledge and innovation. Under the landmark of the innovation education mode is mainly carried out based on the above three conditions.

Based on the above three conditions, we took some effective measures:

\section{- THE COURSE CONSTRUCTION}

As early as in 2006, our school open a door to psychology courses. The teacher told the students about innovative stories, and a variety of innovative ways during the class. Its purpose is to break the worship of authority, and encourage students to dare to difficult question, everywhere and whenever students' brains should in a condition of "backward thinking", in order to found the problem, and then put forward innovative ideas and solutions. Here, the suggestions have be proposed that faculty and doctoral students should set up senior 54 classes of TRIZ theory ; the master's 36 hours general TRIZ theory courses, and 18 hours of TRIZ elective courses for undergraduate students ,according to the characteristics of the higher education of our country. So that all levels of college students can master the innovation theory and technology to a certain extent, and then go to work quickly after using innovative technology to serve national construction[5].

\section{- THE PLATFORM CONSTRUCTION}

The construction of platform is mainly divided into two aspects. On the one hand, platform construction is the school, our school has already built two provincial laboratory, four provincial engineering research center and five college laboratory. On the other hand is the off-campus platform construction .our school keeps a close relation of cooperation with several outside enterprises, to recommend the students to enter in the enterprise to carry on the practice every year, striving to apply the campus learning innovation theory and the method to practice and achieve the function of the high education. From around the world, most countries attaches great importance to the combination of education and society, in combined with the industry in the aspect of higher education. Many countries and regions of high and new technology industrial park, such as silicon valley in the United States, Japan Tsukuba has several or even dozens of universities as a technical support. Therefore, we must strengthen the combination of college, enterprise and scientific research institutions, so that the students in the practice of scientific research, production, can be trained practical ability to innovate[6].

\section{- HOLDING TRAINING SEMINARS}

The updating knowledge has made individual not support complex work, so we must change the individual knowledge into a Shared, organized knowledge. The training seminar will provide a platform of knowledge transformation.

\section{CONCLUSIONS}

Innovation is not just a concept and a mature theoretical system. As we know, ithas a specific realization methods and tools. Innovation needs arousing and cultivating by a means of students' education. To implement innovation education should be based on TRIZ theory as the instruction, take mind 
mapping as an auxiliary tool, so that colleges and universities cultivate a new generation of talents with innovative thinking and ability.

\section{ACKNOWLEDGEMENTS}

Authors are grateful for support from key research subject of Jilin province higher education teaching research.

\section{REFERENCE}

[1] Guo Yu, Liao Wenhe, Chen Xiaosheng. "TRIZ Theory and Innovation Ability Training". Journal of Nanjing University of Aeronautics \& Astronautics( Social Sciences), 2005,7(3): 79-82. (In Chinese)

[2] Qiao Haishu, Li Yuanhang. "Sum up the Training of the Creative Abilityof College
Student". University Education Science, 2008, (1): 20-23(In Chinese).

[3] Terninko,J., Zusman, A., \& Zlotin, B. "Systematic Innovation: Anintroduction to TRIZ”. FL: CRC, Press. 1998.

[4] TRIZ.http://en.wikipedia.org/wiki/Innovation

[5] Introduction to the Independent Innovation . Innovation,2006,(02)(In Chinese)

[6] Qing Wang, Jingru Bai, Zhang Bai, Chunxia Jia, "Training methods of theory ofTRIZ for engineering college students" [J].Energy Education Science and Technology Part B: Social and Educational Studies. 2012Volume (issue)Special Issue 2:49-54 